\title{
Economic and disease burden of RSV- associated hospitalizations in young children in France, from 2010 through 2018
}

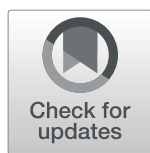

C. Demont ${ }^{1 *}$, N. Petrica ${ }^{2}$, I. Bardoulat ${ }^{2}$, S. Duret ${ }^{2}$, L. Watier ${ }^{3}$, A. Chosidow ${ }^{4}$, M. Lorrot ${ }^{4}$, A. Kieffer ${ }^{1}$ and M. Lemaitre ${ }^{2}$

\begin{abstract}
Background: Respiratory syncytial virus (RSV) is the main cause of infant and child hospitalizations. The study objective is to estimate the RSV-associated hospitalizations and economic burden in young children in France to inform future preventive strategies.

Methods: We conducted a retrospective analysis of RSV-associated hospitalizations data from the French Hospital database (PMSI-MCO) which covers the entire French population. All children aged $<5$ years hospitalized with RSV ICD-10 codes (J210, J219, J45, J121, J205, R062) from 2010 to 2018, were included. Descriptive analyses were conducted by RSV seasons (Oct to March), by respiratory years (July to June) and per age groups.

Results: On average 50,878 RSV-associated hospitalizations (range: 43,715 - 54,616) per season was reported in France, $69 \%$ among children $<1$ year old. This represents $28 \%$ of all-cause hospitalizations that occurred among children $<1$ year old, and less than 10\% of all-cause hospitalizations in older children. Number of RSV-associated hospitalizations were similar for infants born during (Oct-March) or outside (April-September) their first RSV season. The highest risk being reported for infants born from September through November. The associated hospitalization cost increased between 2010 - 11 and 2017-18, from €93.2 million to €124.1 million, respectively, and infants $<1$ year old represented $80 \%$ of the economic burden.
\end{abstract}

Conclusion: RSV is an important cause of child hospitalization in France. The burden on healthcare system is mainly driven by $<1$ year olds, and preventive strategies should be implemented before the first RSV season.

Keywords: Respiratory syncytial virus, Hospitalization, Socio-economic impact, Burden, Children

\section{Introduction}

Respiratory Syncytial Virus (RSV) has been recognized as a major cause of lower respiratory tract infections (LRTI) in children [1] and is the leading cause of hospital admissions in $<1$ year olds [2, 3]. Risk of hospital admissions due to RSV is higher in children with known risk factors (prematurity, comorbidities, age $<6$ months, birth proximity to RSV season) [1, 3, 4]. Nevertheless, severe outcomes requiring hospital admission often

\footnotetext{
* Correspondence: Clarisse.Demont@sanofi.com

${ }^{1}$ Sanofi Pasteur, 14 Espace Henry Vallée, 69007 Lyon, France

Full list of author information is available at the end of the article
}

occur in previously healthy children [5]. Treatment is mainly based on supportive care and the monoclonal antibody palivizumab is the only available prophylactic strategy indicated in restricted at-risk pediatric populations to prevent RSV-related complications, including hospitalizations [6, 7].

In Northern Europe, respiratory tract infections associated with RSV generally occur between October and March, with a peak of infection in France around November/December [8]. Every year, French surveillance data suggests that $30 \%$ of children aged $<2$ years have bronchiolitis, mostly due to RSV, of which $2-3 \%$ are

C C The Author(s). 2021 Open Access This article is licensed under a Creative Commons Attribution 4.0 International License, which permits use, sharing, adaptation, distribution and reproduction in any medium or format, as long as you give appropriate credit to the original author(s) and the source, provide a link to the Creative Commons licence, and indicate if changes were made. The images or other third party material in this article are included in the article's Creative Commons licence, unless indicated otherwise in a credit line to the material. If material is not included in the article's Creative Commons licence and your intended use is not permitted by statutory regulation or exceeds the permitted use, you will need to obtain permission directly from the copyright holder. To view a copy of this licence, visit http://creativecommons.org/licenses/by/4.0/ The Creative Commons Public Domain Dedication waiver (http://creativecommons.org/publicdomain/zero/1.0/) applies to the data made available in this article, unless otherwise stated in a credit line to the data. 
hospitalized and less than 1\% leads to death [9]. In 2009, a national French study reported an overall incidence of hospital admissions for bronchiolitis of 35.8 per 1000 children < 1 year old [10]. In 2018, in a single centre study by Kramer et al., the incidence of hospital admissions for RSV infection during the first year of life was estimated to be 14.5 per 1000 births [11].

RSV clinical burden is associated with high direct costs related to healthcare consumption. To our knowledge, the economic burden of RSV related hospitalizations in France was only recently assessed by Kramer et al., the mean cost for RSV hospitalization was estimated to $€ 3,973$ per child $<1$ year old [11]. In a recent US study, a wide range of annual costs based on risk was observed from $\$ 8,000$ up to $\$ 40,000$ [12].

With the approaching launch of new and innovative immunization strategies, such as maternal vaccination or monoclonal antibodies, it has become highly relevant to provide contemporary data on RSV disease burden and healthcare associated cost in countries where these informations are lacking, such as France. The uniqueness of French national health insurance covering 67 million inhabitants is an opportunity to evaluate and update RSV disease burden at hospital [13].

The aim of this study was to provide detailed information on clinical and economic burden at a population level of RSV-associated hospitalization in children aged $<5$ years in France between 2010 and 2018, with a specific focus on children $<1$ year old. This will provide the background evidence related to RSV disease burden before immunization strategies become available.

\section{Methods}

\section{Data sources}

Data were extracted from the French national hospital discharge database (Programme de Médicalisation des Systèmes d'Information - PMSI), covering the whole population [13]. PMSI provides medico-administrative information on secondary and tertiary care from the public and private sectors as described previously [14]. Study was carried out in compliance with the French regulatory [15].

\section{a) Hospitalization data}

All RSV-associated hospital stays in general medicine, surgery and obstetric medical facilities (PMSI-MSO) as well as all-cause hospitalization from 2010 through 2018 in children aged $<5$ years were selected for this analysis. RSV-associated hospitalization were identified using the following International Classification of Diseases 10th revision (ICD-10) codes as the primary diagnosis (PD): J210 (acute bronchiolitis due to RSV), J219 (acute bronchiolitis, unspecified), J121 (pneumonia due to RSV),
J205 (bronchitis due to RSV), J45 (asthma) and R062 (wheezing).

Hospital admissions with an ICD-10 code of bronchiolitis (J210 or J219 ICD-10 codes) recorded as an associated diagnosis (AD) were also selected when the primary diagnosis was a "disorder of the respiratory system" (J00J99 ICD-10 codes) or "certain conditions originating in the perinatal period" (P00-P96 ICD-10 codes), assuming that RSV-associated bronchiolitis contributed to the hospitalization despite not being listed as primary diagnosis.

\section{b) Demographic data}

Monthly births recorded and published by the National Institute of Statistics and Economic Studies (INSEE) were used to estimate the incidence of RSV in France for the 2010-2018 period [16].

\section{Statistical analyses}

A descriptive analysis of RSV-associated hospitalizations during RSV seasons (defined from October to March the following year) was carried out over the period 20102018 [17].

Analyses were stratified by age group, defined by chronological ages ( $<1$ year old vs. $\geq 1$ year old) and further stratified by month categories and by gestational weeks at birth (weeks' gestational age, wGA).

wGA was determined based on mother's information on the number of weeks of amenorrhea, directly available in PMSI database. Data on mother's amenorrhea was not consistently available, especially for records of children born before 2009. Full term birth was defined as birth after 36 weeks of amenorrhea, otherwise it was considered as preterm birth, for which subcategories were defined: extremely preterm birth $(<29$ weeks), very preterm birth (29-32 weeks) and moderate preterm birth (33-35 weeks). The stratification was based on the palivizumab recommendations of the healthcare authorities and the society of neonatology in France [7].

\section{c) Epidemiological analysis}

RSV-associated hospitalization incidence was estimated by the number of RSV-associated hospitalizations per 1000 person-months for each RSV season. Total time of exposure was calculated from demographic data, corresponding to the number of months during which children in specific age subgroups were at risk for RSV, during the season. Incidence was also estimated for the respiratory year, defined from July to June the following year to ensure that an entire RSV season was covered.

We assessed if the month of birth has an impact on the risk of RSV hospitalization. For children born during 
a given month, the number of RSV-associated hospitalizations was computed from birth to the end of their first RSV season. The RSV-associated hospitalization risk across the 8 RSV seasons was determined by dividing the total number of RSV-associated hospitalisations from the total number of children born during the same month. For this risk estimation, a more restrictive definition of RSV-associated hospitalizations was considered excluding J45 (asthma) and R062 (wheezing).

Children characteristics were described considering the age, the gender and the known risk factors for RSVassociated hospitalization: presence or absence of congenital heart defects (PD, related diagnosis (RD) or $\mathrm{AD}$ ICD-10 Q20-Q26 in hospital discharge), bronchopulmonary dysplasia (PD, RD or AD ICD-10 P27.1), Down syndrome (PD, RD or AD ICD-10 Q90), cystic fibrosis with pulmonary manifestations (PD, RD or AD ICD-10 Q90, E84).

All-cause hospital admissions occurring within 3 months following the initial RSV-associated hospitalization were identified. The number and proportion of patients affected by re-hospitalization and the average number of re-hospitalizations per patient were estimated.

\section{d) Economic analysis}

Direct cost of RSV burden was calculated based on the resources used during RSV-associated hospitalizations recorded in PMSI database. Total cost and average cost per stay per patient were calculated by RSV season from a collective perspective, considering the French national health insurance reimbursement, medical professionals costs and running costs of the medical unit (e.g. cleaning and laundry), public complementary and private insurance and out-of-pocket charges.

These costs were calculated for all RSV seasons according to the DRG (Diagnosis Related Group) based payment system for reimbursement of acute care (MSO). The costs were adjusted to 2018 euro value by applying the price index of health products in mainland France [16].

\section{Results}

\section{Epidemiologic burden of RSV}

\section{Hospital stays and patients' characteristics}

A total of 407,025 RSV-associated hospitalizations were identified over 8 RSV seasons in children aged $<5$ years (Table 1). A 15\%-increase in RSV-associated hospitalization was observed between 2010/11 ( $N=$ $43,715)$ and 2013/14 ( $N=50,373)$, and $8 \%$ between $2014 / 15(\mathrm{~N}=50,728)$ and 2017/18 $(N=54,616)$. During the 8-year period, RSV-associated hospitalizations among all-cause hospitalizations increased from 22 to $28 \%$ in children < 1 year old during RSV seasons and from 13 to $16 \%$ during respiratory years (Table S1).

RSV-associated hospitalization incidence varied from 1.83 to 2.40 per 1000 person-months (Fig. 1). Incidence in the <1-year old population increased from 6.23 to 8.85 per 1000 person-months, representing $69 \%$ of RSVassociated hospitalizations. RSV-associated hospitalizations of children $<1$ year old were mainly coded as acute bronchiolitis due to RSV (J210-45\%) and acute bronchiolitis - unspecified (J219-48\%) (Fig. S1). In older children, asthma (J45) was the main code used for hospital admission (70\%), especially for children $\geq 2$ years old (89\%).

The risk of RSV-associated hospitalization, during their first RSV season exposure, increased for children born from April up to November (Fig. 2). Children born between September and November were at the highest risk to be hospitalized for RSV ( 4.1 and $5.3 \%$ respectively) compared to other months of birth. A decreased risk of RSV-associated hospitalization was observed for children born from December up to March (3.4 and $0.1 \%$ respectively). The total number of RSV-associated

Table 1 Number of RSV hospital stays, according to age groups and RSV seasons from 2010 through 2018 in France

\begin{tabular}{llllllll}
\hline & & \multicolumn{2}{l}{ Age group (month old) } \\
\cline { 2 - 7 } RSV season/ N & All ages & $\mathbf{<}$ & $\mathbf{3 - 5}$ & $\mathbf{6 - 1 1}$ & $\mathbf{1 2 - 2 3}$ & $\mathbf{2 4 - 3 5}$ & $\mathbf{3 6 - 5 9}$ \\
\hline $2010 / 2011$ & 43,715 & 13,691 & 8146 & 8098 & 7026 & 3105 & 3649 \\
$2011 / 2012$ & 47,973 & 15,351 & 8665 & 8888 & 7730 & 3482 & 3857 \\
$2012 / 2013$ & 50,949 & 17,515 & 9191 & 8562 & 7576 & 3658 & 4447 \\
$2013 / 2014$ & 50,373 & 17,280 & 9476 & 8551 & 7418 & 3471 & 4177 \\
$2014 / 2015$ & 50,728 & 16,572 & 8735 & 8604 & 7472 & 4071 & 5274 \\
$2015 / 2016$ & 54,585 & 18,873 & 10,071 & 9236 & 7918 & 3837 & 4650 \\
$2016 / 2017$ & 54,086 & 18,102 & 10,127 & 9397 & 8109 & 3877 & 4474 \\
$2017 / 2018$ & 54,616 & 18,734 & 10,458 & 9492 & 7752 & 3703 & 4477 \\
Mean annual number & $\mathbf{5 0 , 8 7 8}$ & $\mathbf{1 7 , 0 1 5}$ & $\mathbf{9 3 5 9}$ & $\mathbf{8 8 5 4}$ & $\mathbf{7 6 2 5}$ & $\mathbf{3 6 5 1}$ \\
\hline
\end{tabular}

RSV Respiratory syncytial virus 


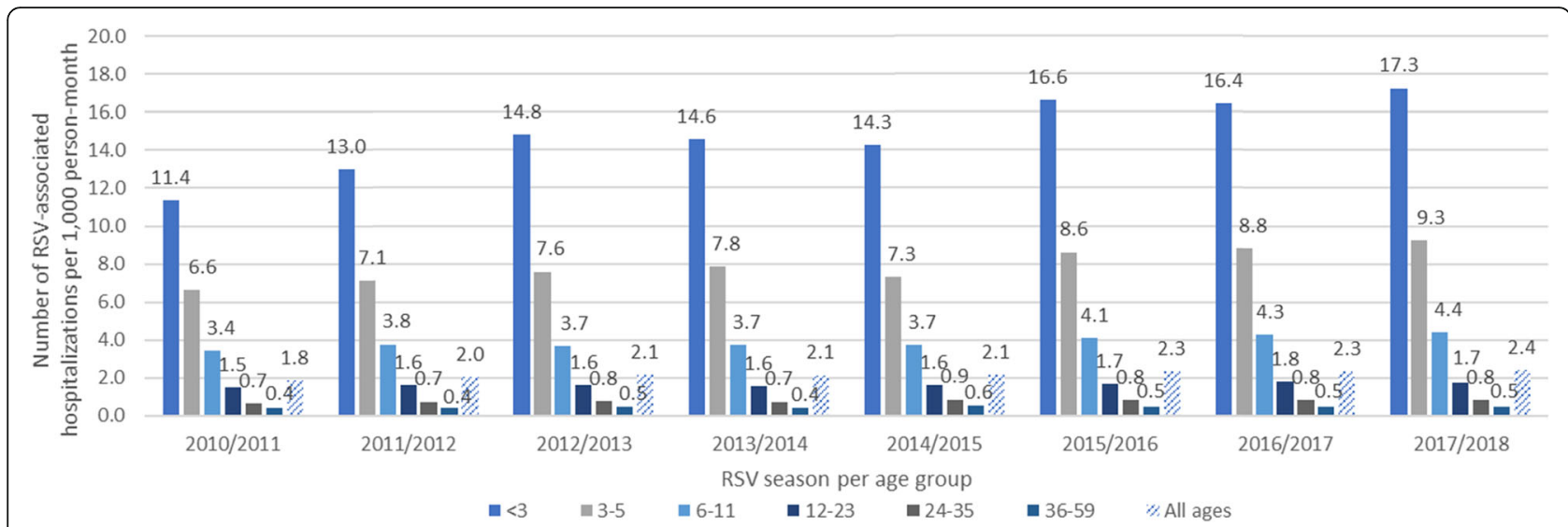

Fig. 1 Rate of RSV-associated hospitalizations, per 1000 person-month, by RSV season and age group, from 2010 through 2018 in France

hospitalizations was comparable between those born outside (April - September) or during RSV season (October - March) with 85,292 versus 96,466 RSVassociated hospitalization over the 8-year period.

Table 2 represents patient characteristics. Approximately $59 \%$ of the children with RSV-associated hospitalizations were male. Among the $74 \%(N=270,048)$ children aged $<5$ years whose gestational age was known $89 \%(N=241,625)$ were born at term ( $\geq 36$ wGA). Among preterm infants, $16 \%(N=4497)$ were extremely preterm and $56 \%(N=16,018)$ moderate preterm infants.
Regarding other characteristics, 3\% $(N=11,043)$ had congenital heart defect, $1.2 \%(N=4249)$ had bronchopulmonary dysplasia, $0.4 \%(N=1303)$ had Down syndrome and $<0.1 \%(N=166)$ had cystic fibrosis with pulmonary manifestations. In total, $87 \%(N=40,009)$ of RSV-associated hospitalized children were otherwise healthy (median presented in Table 2).

Over the 8-year period, 89\% of RSV-associated hospitalizations were inpatient stays (at least 1 night) with a median length of stay of 3 nights. This median was 3 nights [Q1-Q3: 2-5] for children < 1 year old and 2

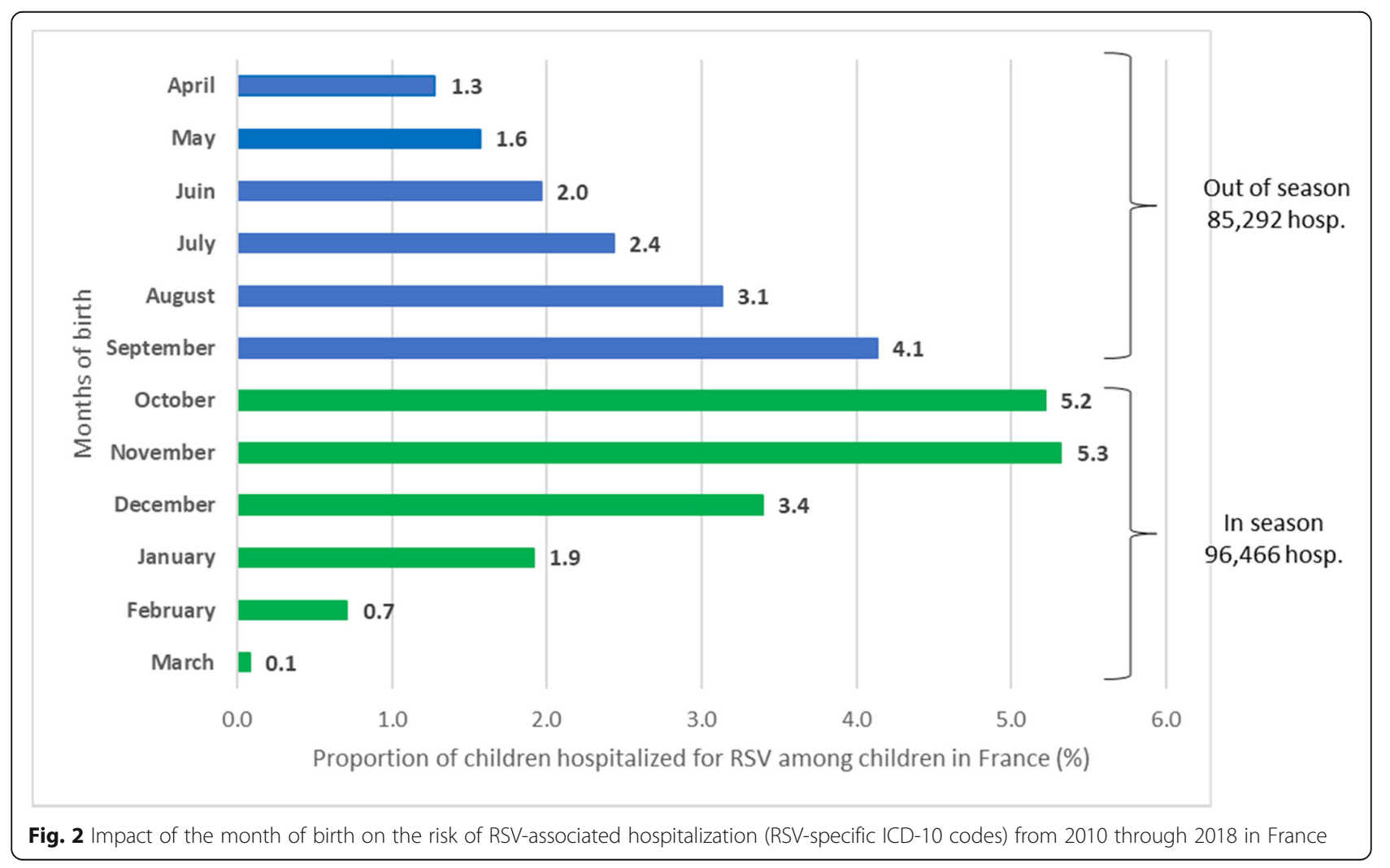


Table 2 Summary of patient characteristics, seasonal median calculated over the results recorded for each RSV season (2010-2018 RSV seasons), per age group and gestational age at birth in France

\begin{tabular}{|c|c|c|c|c|}
\hline & \multicolumn{2}{|l|}{ Age group } & \multicolumn{2}{|c|}{ Preterm/term status ${ }^{a}$} \\
\hline & $\begin{array}{l}<1 \text { year old } \\
\mathrm{N} \text { median }=31,570\end{array}$ & $\begin{array}{l}\geq 1 \text { year old } \\
N \text { median }=14,418\end{array}$ & $\begin{array}{l}\text { Preterm } \\
\mathrm{N} \text { median }=3616\end{array}$ & $\begin{array}{l}\text { Term } \\
\mathrm{N} \text { median }=31,091\end{array}$ \\
\hline \multicolumn{5}{|c|}{ Number of males } \\
\hline Median & 18,296 & 8838 & 2120 & 18,332 \\
\hline Range & $15,629-19,728$ & $7681-9554$ & $1706-2257$ & $12,334-20,051$ \\
\hline \multicolumn{5}{|c|}{ Comorbidities } \\
\hline \multicolumn{5}{|c|}{ Congenital heart defect } \\
\hline Median & 945 & 513 & 573 & 756 \\
\hline Range & $749-1020$ & $173-595$ & $359-635$ & $421-868$ \\
\hline \multicolumn{5}{|c|}{ Bronchopulmonary dysplasia } \\
\hline Median & 304 & 243 & 495 & 31 \\
\hline Range & $251-340$ & $140-275$ & $330-559$ & $21-40$ \\
\hline \multicolumn{5}{|c|}{ Down syndrome } \\
\hline Median & 106 & 61 & 18 & 122 \\
\hline Range & $69-118$ & $35-86$ & $13-26$ & $62-149$ \\
\hline \multicolumn{5}{|c|}{ Cystic fibrosis with pulmonary manifestations } \\
\hline Median & 12 & 8 & 2 & 15 \\
\hline Range & 6-19 & $5-12$ & $0-4$ & $8-22$ \\
\hline
\end{tabular}

RSV Respiratory syncytial virus

$\mathrm{N}$ median: median annual number of patients

${ }^{a}$ Only for children having determined gestational age

nights [Q1-Q3: 1-3] for children $\geq 1$ year old. In children $<1$ year old with known wGA at delivery, similar median was observed for preterm $(<36 \mathrm{wGA})$ and term children, equal to 3 nights (Table 3). Preterm children $<3$ months had a median length of stay equal to 5 [Q1-Q3: 2-8] nights (Table S2). The highest average length of stay was observed in extremely preterm children $(<29$ wGA) aged $<3$ months (30 nights) (data not shown).

Three percent of RSV-associated hospitalizations $(N=$ 12,496 stays) were followed by an admission to intensive care unit (ICU). Around 95\% of these ICU stays were reported in children $<1$ year old and more than half were observed in term children (Table 3). The median rate of RSV-associated hospitalizations with ICU admission was $4.2 \%$ [range 3.3-5.2\%] for children $<1$ year old and $0.5 \%$ [range 0.4-0.6\%] for children $\geq 1$ year old. Children $<3$ months recorded a higher median rate of RSVassociated hospitalizations with ICU admission equal to 7\% [range 6.2-8.8\%] (Table S2).

A small number of deaths were recorded during RSVassociated hospitalizations, corresponding to less than 13 deaths by RSV season and around two third of $t$ these children had multiple risk factors (68\%) (Table 3). The risk of in-hospital death remained constant during the study period.

Twenty-one percent of children were hospitalized (allcauses considered) in the 3 months following the initial
RSV-associated hospitalization, of which two third (64\%) were $<1$ year old. Twelve percent of children were hospitalized for another RSV episode in the 3 months following the initial RSV-associated hospitalization, this rate was two times higher for the preterm (21.6\%) compared to term children (11.1\%) (Table 3).

\section{Economic burden of RSV}

Over the 8-year period the total direct cost of RSVassociated hospitalizations was estimated at $€ 931.6$ million (Table 4). Annual costs increased between 2010 and 11 and 2017-18, from €93.2 million to €124.1 million, consistently with the growing number of RSV-associated hospitalizations. The average cost of RSV-associated hospitalization, estimated at $€ 2289$ (SD 2114) in children aged $<5$ years old, decreased with age, being 2 times higher for infants aged of $<3$ months compared to the oldest children (36-59 months) (Fig. 3). In children $<1$ year old, the mean cost was estimated at $€ 2607$ (SD 2317). Irrespective of the season, RSV-associated hospitalizations in children $<1$ year old represented almost $80 \%$ of the total cost, of which half was generated by hospital stays of infants $<3$ months. The average RSVassociated hospitalization cost of a child with at least one risk factor was estimated at $€ 2947$ (SD 3809) compared to $€ 2208$ (SD 1781) for children without risk factor (data not shown). RSV-associated hospitalization of 
Table 3 Summary of the characteristics of RSV-associated hospitalizations, seasonal median calculated over the results recorded for each RSV season (2010-2018 RSV seasons), by age group and preterm status in France

\begin{tabular}{|c|c|c|c|c|}
\hline & \multicolumn{2}{|l|}{ Age group } & \multicolumn{2}{|c|}{ Preterm/term status ${ }^{a}$} \\
\hline & $<1$ year old & $\geq 1$ year old & Preterm & Term \\
\hline \multicolumn{5}{|c|}{ Number of RSV patients } \\
\hline Median & 31,570 & 14,418 & 3616 & 31,091 \\
\hline Range & $26,885-33,952$ & $12,606-15,485$ & 2889-3875 & $21,159-34,141$ \\
\hline \multicolumn{5}{|c|}{ Length of RSV inpatient hospitalisation ${ }^{b}$} \\
\hline Median (days) & 3 & 2 & 3 & 3 \\
\hline Range & $2-5$ & $1-3$ & $2-6$ & $2-5$ \\
\hline \multicolumn{5}{|c|}{ Rate of hospital stays with transition to intensive care } \\
\hline Median (\%) & $4.2 \%$ & $0.5 \%$ & $6.0 \%$ & $3.0 \%$ \\
\hline Range & $3.3-5.2 \%$ & $0.4-0.6 \%$ & $5.1-7.2 \%$ & $2.7-3.7 \%$ \\
\hline \multicolumn{5}{|c|}{ Number of hospital death } \\
\hline Median & 6.5 & 3.5 & 1.5 & 8 \\
\hline Range & $4-10$ & $0-8$ & $0-3$ & $5-12$ \\
\hline \multicolumn{5}{|c|}{ 3-month readmission rate } \\
\hline \multicolumn{5}{|l|}{ All cause } \\
\hline Median (\%) & $22.9 \%$ & $17.9 \%$ & $35.1 \%$ & $21.2 \%$ \\
\hline Range & $22.0-23.6 \%$ & $17.1-18.9 \%$ & $34.1-39.3 \%$ & $20.6-22.2 \%$ \\
\hline \multicolumn{5}{|l|}{ RSV } \\
\hline Median (\%) & $12.7 \%$ & $8.7 \%$ & $21.6 \%$ & $11.1 \%$ \\
\hline Range & $11.6-13.7 \%$ & $8.2-9.2 \%$ & $19.9-24.6 \%$ & $10.4-11.8 \%$ \\
\hline
\end{tabular}

RSV Respiratory syncytial virus

${ }^{a}$ Only for children having determined gestational age

${ }^{\mathrm{b}}$ Calculated overall RSV seasons

term children generated $66 \%$ of the total cost, from $€ 52.5$ million in $2010 / 2011$ to $€ 85.6$ million euros in 2017/18 (considering term and unknown wGA children, it represents $89 \%$ of the total cost: $€ 83.3$ million in 2010/ 11 and 110.2 million in 2017/18).

Among all RSV-associated hospitalizations, 330 (0.1\%) corresponded to birth hospitalizations. The total cost of these stays represented $€ 6.7$ million euros $(0.7 \%$ of the total costs estimated within the 2010-2018 period).
After excluding these stays, the average cost of RSVassociated hospitalization in infants aged $<3$ months old was estimated at $€ 2911$ (SD 2388) and the total cost of RSV-associated hospitalizations over the study period was estimated at $€ 924$ million for all age groups and at $€ 728$ million euros for the children $<1$ year old, corresponding to an average annual cost of $€ 91$ million. The total cost of stays for children < 1 year old coded J45/ R062 was estimated at $€ 28.7$ million (average annual cost

Table 4 RSV total hospitalization cost by age range during RSV periods between 2010 and 2018 in France

\begin{tabular}{|c|c|c|c|c|c|c|c|}
\hline & & & Age Range (month old) & & & & \\
\hline RSV season & $<3 \mathrm{mo}$ & $3-5 \mathrm{mo}$ & 6-11 mo & $12-23 \mathrm{mo}$ & $24-35 \mathrm{mo}$ & $36-59 \mathrm{mo}$ & Total \\
\hline 2010/2011 & $37,006,869 €$ & $18,373,618 €$ & $16,320,666 €$ & $12,072,373 €$ & $4,554,388 €$ & $4,847,626 €$ & $93,175,540 €$ \\
\hline $2011 / 2012$ & $41,167,182 €$ & $20,126,198 €$ & $18,320,858 €$ & $13,393,522 €$ & $5,029,325 €$ & $4,952,583 €$ & $102,989,668 €$ \\
\hline $2012 / 2013$ & $49,873,208 €$ & $21,415,497 €$ & $17,307,913 €$ & $13,152,263 €$ & $5,440,949 €$ & $5,839,329 €$ & $113,029,159 €$ \\
\hline $2013 / 2014$ & $47,793,614 €$ & $22,214,521 €$ & $17,390,682 €$ & $12,586,276 €$ & $5,152,541 €$ & $5,555,681 €$ & $110,693,315 €$ \\
\hline $2014 / 2015$ & $44,380,454 €$ & $19,406,961 €$ & $16,817,894 €$ & $12,519,617 €$ & $5,881,104 €$ & $6,994,634 €$ & $106,000,664 €$ \\
\hline $2015 / 2016$ & $62,859,377 €$ & $27,329,493 €$ & $20,818,388 €$ & $14,531,938 €$ & $5,786,835 €$ & $6,101,165 €$ & $137,427,195 €$ \\
\hline $2016 / 2017$ & $64,312,635 €$ & $29,300,573 €$ & $22,819,097 €$ & $15,643,755 €$ & $6,059,861 €$ & $6,030,519 €$ & $144,166,440 €$ \\
\hline $2017 / 2018$ & $54,565,966 €$ & $24,924,750 €$ & $19,856,450 €$ & $13,186,120 €$ & $5,538,018 €$ & $6,039,978 €$ & $124,111,282 €$ \\
\hline Mean annual cost & $50,244,913 €$ & $22,886,451 €$ & $18,706,494 €$ & $13,385,733 €$ & $5,430,378 €$ & $5,795,189 €$ & $116,449,158 €$ \\
\hline
\end{tabular}




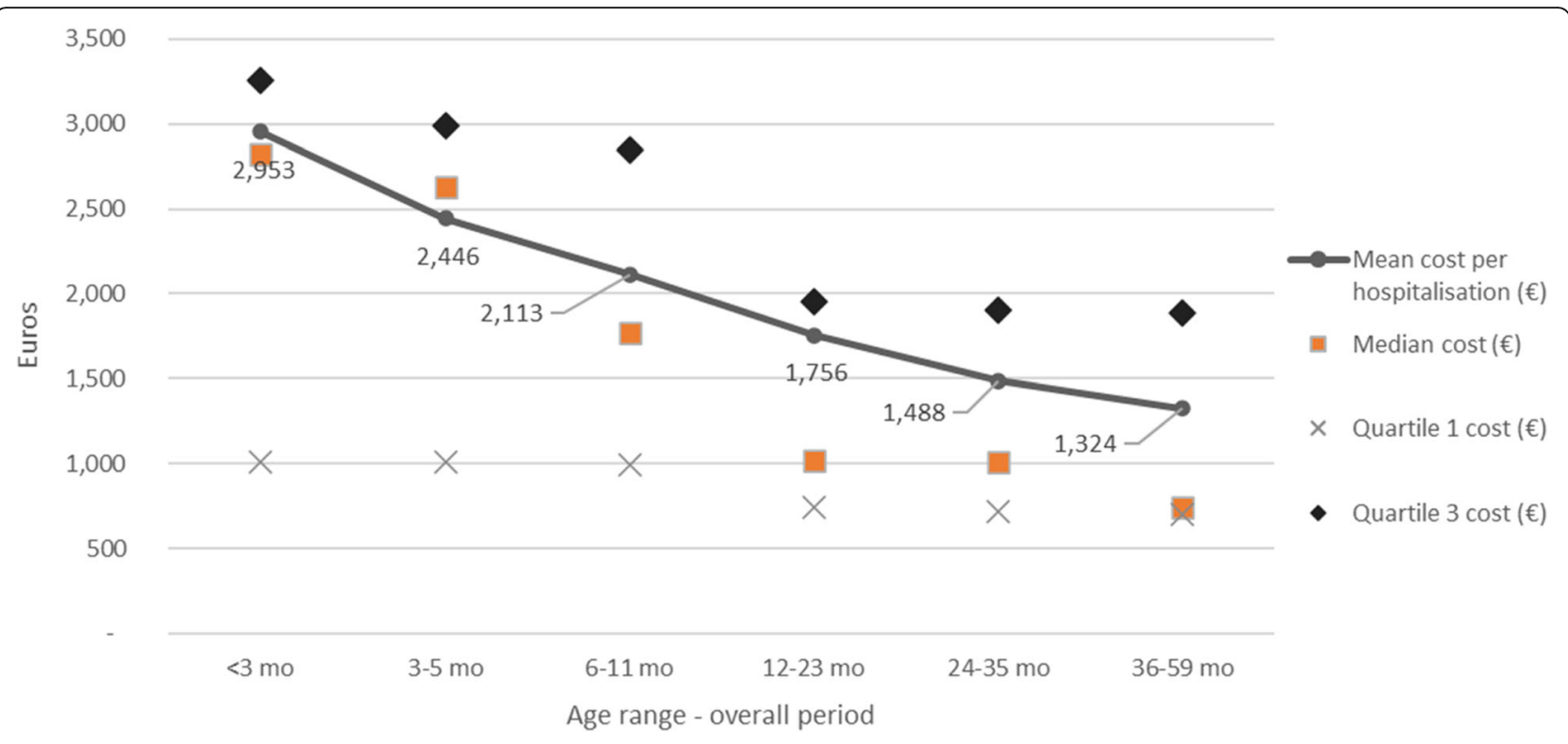

Fig. 3 RSV associated hospitalization cost distribution by age group during RSV seasons from 2010 through 2018 in France

$€ 3.6$ million), representing $3.9 \%$ of the total cost for children $<1$ year old estimated over the entire study period.

\section{Discussion}

This study is the first to describe the national burden of RSV-associated hospital admissions in children aged $<5$ years in France during a large time period (2010-2018). The incidence rate of RSV-associated hospitalization increased over time from 1.3 to 2.4 per 1000 personmonths. Children $<1$ year old were the most impacted by RSV-associated hospitalizations as they represent $69 \%$ of the hospitalizations, with associated high costs. We observed a correlation between month of birth and RSVassociated hospitalization and an equal distribution of RSV-associated hospitalization from infants born outside or during the RSV season.

Since the virological test is not systematically requested, the decision to include J219: "acute bronchiolitis, unspecified" in addition to RSV specific ICD-10 are J210, J121 and J205 was made to limit the underestimation of RSV-hospitalizations. This observation was highlighted by Cai et al. who showed that RSV-specific ICD-10 codes had a sensitivity of 14\% Adding J219 in our analysis increased the sensitivity without compromising the specificity [17]. Furthermore, a recent laboratory surveillance report from Lyon hospital centres (HCL, France) showed that the incidence of hospitalization with a confirmed RSV in the first 3 months of life for children between September and November was equal to $3.45 \%$ (unpublished data). This result is close to our estimation (incidence rate 3.37\%, same age and year) which validates the ICD-10 codes selected for this study.
The rising trend of incidence over time has already been described in other studies, particularly in the United Kingdom [18, 19]. According to the authors, this observed increase was unlikely due to changes in disease incidence or severity, but mostly reflected the increase in hospital admissions observed for the last 15 years [20]. This could be attributed to the lowering of hospital admission thresholds and the decline in management of acute outcomes at the community. In France over the last 15 years, a $45 \%$ increase of outpatient visits has been observed in hospital setting [21]. A complementary analysis of our data showed that the incidence of RSV hospital outpatient visit and the incidence of RSV hospital inpatient stays have increased during the 8-year period, respectively from 0.19 to 0.28 per 1000 person-months and 1.6 to 2.1 per 1000 person-months (Table S4). Changes in air pollution could have contributed to this increasing of RSV-associated hospitalization incidence. A 2018 study in Paris showed that winter air pollution was positively associated with both outpatient visits and hospitalizations in the occurrence of acute severe bronchiolitis [22].

In our study, we observed a negative correlation between RSV-associated hospitalization incidence and age groups, most of the burden being observed among children $<1$ year old. This trend was also described by other studies [14, 18, 19]. Our findings, from 37 to 53 RSV hospitalizations per 1000 personyears in infants < 1 year of age between 2010 and 2018, is in accordance with the French study conducted using the PMSI database in 2009 with a bronchiolitis-associated hospitalization rate of 35.8 per 1000 infants [10]. RSV-associated hospitalization rates 
were the highest for children born between September and November and early exposed to their first RSV season. This result has been reported in previous studies such as the study from Kramer et al. [11], where the highest risk of RSV-associated hospitalization was observed for children born in November. Lloyd et al. reported the highest risk of RSVassociated hospitalization in the first year of life for children born between October and February with a peak in December followed by a decrease until April [24]. In our study, the risk of RSV-associated hospitalization decreased from November to March, which can be explained by maternal exposure to RSV during pregnancy during the early months of the winter epidemic. The transfer of maternal RSV antibodies to the foetus then confers protection of the child against the virus after birth $[25,26]$. In our results we also show a similar number of RSV-associated hospitalizations, between infants born outside or during RSV season exposed to their first RSV season. The same observation could be derived from studies by Lloyd et al. and Reeves et al. [24, 27]. This finding may support RSV immunization of all infants before the RSV season, as discussed by Janet et al. [28].

Regarding the economic burden of RSV, the average annual cost due to RSV hospitalizations was estimated at $€ 116$ million, with a mean cost per stay of $€ 2289$, of the same order of magnitude as that reported in the Danish study (around $€ 1830$ ) [23]. Similar to the number of hospitalizations, the total cost increased over the time period, mainly among infants $<1$ year that represents $80 \%$ of the total cost of hospitalizations in our study. Hospital admissions of preterm children (7\% of all RSV hospitalizations) generated $11 \%$ of the total costs. These elements echo the results of another study which evaluated the long-term RSV burden among pre-term and term infants in the US, that also reported prematurity and young age group ( $<1$ year old) as risk factors linked to high economic burden [29]. In comparison, the French study from Kramer showed a higher hospitalization cost in children $<1$ year old compared to our results illustrating the cost heterogeneity across the country [11].

One limitation of our study, was the inclusion of asthma and wheezing ICD-10 codes, non-specific of RSV infections. Interestingly, asthma became the main cause of hospital admission in children $\geq 1$ year old during the epidemic months (50\% of hospitalisations among children aged between 1 and 2 years old and $90 \%$ in children $>2$ years old). This observation is in agreement with other studies [5], and most probably because children $\geq 1$ year old are not systematically tested for RSV. Therefore, the virus involved is not always mentioned in hospital discharges, leading to underestimate the RSV hospitalization burden when RSV specific codes are used alone. Moreover, we observed a similar temporal distribution of asthma vs RSV-associated hospitalization codes (data not shown) during the RSV season and especially at its peak, making asthma related hospitalization a good proxy for RSV hospitalization in older children.

\section{Conclusion}

This study describes the high burden of RSV-associated hospitalizations in French children and mostly in the $<1$ year old population with an associated average annual cost of $€ 91$ million. During the last RSV season studied 201718, RSV-associated hospitalizations alone accounted for $28 \%$ of all-cause hospitalizations among children $<1$ year old. We also demonstrated healthcare system pressure in France every winter due to RSV-hospitalizations from infants born inside and outside their first RSV season. This approach could be complemented by RSV burden estimates in community setting or using ecological approach to estimate hospitalization attributable to RSV using excess modelling method [30, 31].

\section{Supplementary Information}

The online version contains supplementary material available at https://doi. org/10.1186/s12879-021-06399-8.

Additional file 1: Table S1. Number of all-causes hospitalizations and percentage of RSV associated hospitalizations among all-causes hospitalizations by age group and type period (RSV season and year (July-June)), from 2010 to 2018 in France. Table S2. Summary of the characteristics of the hospitalizations for RSV infection for $<3$ months old group, median indicator calculated over the indicators recorded for each RSV season (2010-2018 RSV seasons), total and per gestational age at birth in France.

Table S3. Incidence of RSV hospitalizations during the respiratory year (July N - June N + 1) between 2010 and 2018 (per 1000 person-years). Table S4. Rate of RSV-related hospital inpatient/outpatient stays per 1000 person-months. Fig. S1. Breakdown of RSV-associated hospitalizations by RSV-specific ICD-10 codes among primary and associated diagnoses, stratified by age group from 2010 through 2018 in France.

\section{Acknowledgements}

We thank Sandra Chaves for her comments on the draft of the manuscript. Editorial support for this manuscript was provided by Anirban Sanyal (Sanofi).

\section{Authors' contributions}

All authors were responsible for the reported research, have participated in the concept and design, critically reviewed the final draft of the manuscript, and have approved the manuscript as submitted. NP and Magali Lemaitre were responsible for data analysis. CD, LW, AC, Mathie Lorrot, AK contributed to the interpretation of the data. NP, SD, IB prepared the first draft of the manuscript.

\section{Funding}

This study was funded by Sanofi Pasteur and AstraZeneca.

\section{Availability of data and materials}

All data generated or analysed during this study are included in this published article and its supplementary files.

The data that support the findings of this study are available from the Technical Agency for Information on Hospital Care - ATIH (PMSI holder). But restrictions apply to the availability of these data, which were used with an authorization for the current study, and so are not publicly available. 


\section{Declarations}

\section{Ethics approval and consent to participate}

This non-interventional study does not fall under the scope of the law and does not require any ethics committee submission (Law 88-1138 relative to Biomedical Research of December 20, 1988, modified on August 9, 2004). The ATIH (Agence Technique de I'Information sur I'Hospitalisation) is responsible for managing the finalized PMSI database each year under approval by the CNIL (National commission for data processing and civil liberties). According to French Regulation, obtaining written consent does not apply to research work using such medico-administrative database. Study was carried out in compliance with the French regulatory.

\section{Consent for publication}

Not applicable.

\section{Competing interests}

NP, SD, Magali Lemaitre and IB are employees of IQVIA. AK and CD are Sanofi employees and may hold shares and/or stock options in the company. AC, Mathie Lorrot and LW had received consulting fees from IQVIA for the study.

\section{Author details}

${ }^{1}$ Sanofi Pasteur, 14 Espace Henry Vallée, 69007 Lyon, France. ${ }^{2}$ IQVIA, 92400 Courbevoie, France. ${ }^{3}$ Université Paris-Saclay, UVSQ, Inserm, CESP, 94807 Villejuif, France. ${ }^{4}$ Department of Pediatrics, Armand Trousseau Hospital (AP-HP), 75012 Paris, France.

Received: 2 February 2021 Accepted: 15 July 2021 Published online: 02 August 2021

\section{References}

1. Shi T, McAllister DA, O'Brien KL, Simoes EAF, Madhi SA, Gessner BD, et al. Global, regional, and national disease burden estimates of acute lower respiratory infections due to respiratory syncytial virus in young children in 2015: a systematic review and modelling study. Lancet. 2017;390(10098): 946-58. https://doi.org/10.1016/S0140-6736(17)30938-8.

2. Paes BA, Mitchell I, Banerji A, Lanctôt KL, Langley JM. A decade of respiratory syncytial virus epidemiology and prophylaxis: translating evidence into everyday clinical practice. Can Respir J. 2011;18(2):e10-9. https://doi.org/10.1155/2011/493056.

3. Bont L, Checchia PA, Fauroux B, Figueras-Aloy J, Manzoni P, Paes B, et al. Defining the epidemiology and burden of severe respiratory syncytial virus infection among infants and children in Western countries. Infect Dis Ther. 2016;5(3):271-98. https://doi.org/10.1007/s40121-016-0123-0.

4. Blanken $\mathrm{MO}$, Rovers MM, Molenaar JM, Winkler-Seinstra PL, Meijer A, Kimpen $J L L$, et al. Respiratory syncytial virus and recurrent wheeze in healthy preterm infants. N Engl J Med. 2013;368(19):1791-9. https://doi.org/10.1056/ NEJMoa1211917.

5. Hall CB, Weinberg GA, Iwane MK, Blumkin AK, Edwards KM, Staat MA, et al. The burden of respiratory syncytial virus infection in young children. $\mathrm{N}$ Engl J Med. 2009;360(6):588-98. https://doi.org/10.1056/NEJMoa0804877.

6. Barr R, Green CA, Sande CJ, Drysdale SB. Respiratory syncytial virus: diagnosis, prevention and management. Therapeutic Advances in Infection. 2019;6:204993611986579. https://doi.org/10.1177/2049936119865798.

7. Haute Autorite de Sante. Synagis - Comission de la transparence, 5 avril 2017 [Internet]. [cited 2020 Apr 22]. Available from: https://www.has-sante. fr/upload/docs/evamed/CT-15884_SYNAGIS_QD_INS_Avis2_CT15884.pdf. Accessed 22 Apr 2020.

8. Obando-Pacheco P, Justicia-Grande AJ, Rivero-Calle I, Rodríguez-Tenreiro C, Sly $P$, Ramilo O, et al. Respiratory syncytial virus seasonality: a global overview. J Infect Dis. 2018;217(9):1356-64. https://doi.org/10.1093/infdis/ jiy056.

9. Grimprel E, Francois P, Olivier C, Fortier G, Thevenieau D, Pautard JC, et al. Epidémiologie clinique et virologique de la bronchiolite du nourrisson. Enquête nationale multicentrique (I). Med Mal Infect. 1993;23:844-50. https://doi.org/10.1016/S0399-077X(05)80361-0.

10. Che D, Nicolau J, Bergounioux J, Perez T, Bitar D. Bronchiolite aiguë du nourrisson en France : bilan des cas hospitalisés en 2009 et facteurs de létalité. Arch Pediatr. 2012;19(7):700-6. https://doi.org/10.1016/j.arcped.2012. 04.015 .
11. Kramer R, Duclos A, Lina B, Casalegno J-S. Cost and burden of RSV related hospitalisation from 2012 to 2017 in the first year of life in Lyon. France Vaccine. 2018;36(45):6591-3. https://doi.org/10.1016/j.va ccine.2018.09.029.

12. McLaurin KK, Farr AM, Wade SW, Diakun DR, Stewart DL. Respiratory syncytial virus hospitalization outcomes and costs of full-term and preterm infants. J Perinatol. 2016;36(11):990-6. https://doi.org/10.1038/jp.2016.113.

13. Bezin J, Duong M, Lassalle R, Droz C, Pariente A, Blin P, et al. The national healthcare system claims databases in France, SNIIRAM and EGB: powerful tools for pharmacoepidemiology. Pharmacoepidemiol Drug Saf. 2017;26(8): 954-62. https://doi.org/10.1002/pds.4233.

14. Boudemaghe T, Belhadj I. Data resource profile: the french national uniform hospital discharge data set database (PMSI). Int J Epidemiol. 2017;46(2):392392d.

15. CNIL. Méthodologie de référence MR-006 - Études nécessitant l'accès aux données du PMSI par les industriels de santé [Internet]. [cited 2020 Sep 22]. Available from: https://www.cnil.fr/fr/declaration/mr-006-etudes-necessitant-la cces-aux-donnees-du-pmsi-par-les-industriels-de-sante. Accessed 3 Sept 2020.

16. Institut national de la statistique et des études économiques (INSEE). Evolution et structure de la population [Internet]. [Population structure and its evolution]. 2020. Available from: https://www.insee.fr/fr/statistiques/1 893198. Accessed 17 June 2020.

17. Cai W, Tolksdorf K, Hirve S, Schuler E, Zhang W, Haas W, et al. Evaluation of using ICD-10 code data for respiratory syncytial virus surveillance. Influenza Other Respir Viruses. 2020;14(6):630-7. https://doi.org/10.1111/irv.12665.

18. Green CA, Yeates D, Goldacre A, Sande C, Parslow RC, McShane P, et al. Admission to hospital for bronchiolitis in England: trends over five decades, geographical variation and association with perinatal characteristics and subsequent asthma. Arch Dis Child. 2016;101(2):140-6. https://doi.org/10.113 6/archdischild-2015-308723.

19. Reeves RM, Hardelid P, Gilbert R, Warburton F, Ellis J, Pebody RG. Estimating the burden of respiratory syncytial virus (RSV on respiratory hospital admissions in children less than five years of age in England, 2007-2012. Influenza Other Respir Viruses. 2017:11(2):122-9. https://doi.org/10.1111/irv.12443.

20. Gill PJ, Goldacre MJ, Mant D, Heneghan C, Thomson A, Seagroatt V, et al. Increase in emergency admissions to hospital for children aged under 15 in England, 1999-2010: national database analysis. Arch Dis Child. 2013;98(5): 328-34. https://doi.org/10.1136/archdischild-2012-302383.

21. Naouri D, El Khoury C, Vincent-Cassy C, Vuagnat A, Schmidt J, Yordanov Y, et al. The French emergency national survey: a description of emergency departments and patients in France. Bouchama A, editor. PLoS One. 2018; 13(6):e0198474. https://doi.org/10.1371/journal.pone.0198474.

22. Ségala C, Poizeau D, Mesbah M, Willems S, Maidenberg M. Winter air pollution and infant bronchiolitis in Paris. Environ Res. 2008;106(1):96-100. https://doi.org/10.1016/j.envres.2007.05.003.

23. Jepsen MT, Trebbien R, Emborg HD, Krause TG, Schønning K, Voldstedlund $M$, et al. Incidence and seasonality of respiratory syncytial virus hospitalisations in young children in Denmark, 2010 to 2015. Euro Surveill. 2018;23(3):17-00163.

24. Lloyd PC, May L, Hoffman D, Riegelman R, Simonsen L. The effect of birth month on the risk of respiratory syncytial virus hospitalization in the first year of life in the United States. Pediatr Infect Dis J. 2014;33(6):e135-40. https://doi.org/10.1097/INF.0000000000000250.

25. Ogilvie MM, Santhire Vathenen A, Radford M, Codd J, Key S. Maternal antibody and respiratory syncytial virus infection in infancy. J Med Virol. 1981;7(4):263-71. https://doi.org/10.1002/jmv.1890070403.

26. Glezen WP, Paredes A, Allison JE, Taber LH, Frank AL. Risk of respiratory syncytial virus infection for infants from low-income families in relationship to age, sex, ethnic group, and maternal antibody level. J Pediatr. 1981;98(5): 708-15. https://doi.org/10.1016/S0022-3476(81)80829-3.

27. Reeves RM, Hardelid P, Panagiotopoulos N, Minaji M, Warburton F, Pebody R. Burden of hospital admissions caused by respiratory syncytial virus (RSV) in infants in England: a data linkage modelling study. J Infect. 2019;78(6): 468-75. https://doi.org/10.1016/j.jinf.2019.02.012

28. Janet S, Broad J, Snape MD. Respiratory syncytial virus seasonality and its implications on prevention strategies. Hum Vaccin Immunother. 2017;14(1): 234-44. https://doi.org/10.1080/21645515.2017.1403707.

29. Chirikov W, Simões EAF, Kuznik A, Kwon Y, Botteman M. Economic-burden trajectories in commercially insured US infants with respiratory syncytial virus infection. 2020:221(8):1244-55 
30. Cromer D, van Hoek AJ, Jit M, Edmunds WJ, Fleming D, Miller E. The burden of influenza in England by age and clinical risk group: a statistical analysis to inform vaccine policy. J Inf Secur. 2014;68(4):363-71.

31. Cromer D, van Hoek AJ, Newall AT, Pollard AJ, Jit M. Burden of paediatric respiratory syncytial virus disease and potential effect of different immunisation strategies: a modelling and cost-effectiveness analysis for England. Lancet Public Health. 2017;2(8):e367-74. https://doi.org/10.1016/ S2468-2667(17)30103-2.

\section{Publisher's Note}

Springer Nature remains neutral with regard to jurisdictional claims in published maps and institutional affiliations.

Ready to submit your research? Choose BMC and benefit from:

- fast, convenient online submission

- thorough peer review by experienced researchers in your field

- rapid publication on acceptance

- support for research data, including large and complex data types

- gold Open Access which fosters wider collaboration and increased citations

- maximum visibility for your research: over $100 \mathrm{M}$ website views per year

At $\mathrm{BMC}$, research is always in progress.

Learn more biomedcentral.com/submissions 